\title{
Sensitivity to chemotherapy/tyrosine kinase inhibitors of mucinous lepidic adenocarcinoma should be tested in a phase III trial?
}

To the Editor:

We have closely read Marianne Paesmans' detailed analysis pertaining to the statistical issues of the IFCT-0504 trial [1], published in her editorial [2]. However, some misunderstandings concerning the biology of nonmucinous and mucinous lepidic adenocarcinomas (L-ADC) led her to propose a phase III trial comparing paclitaxel-carboplatin with erlotinib in mucinous L-ADC cases, as the next logical step following her statistical analysis. Epidermal growth factor receptor (EGFR)-activating mutations are found in $5-22 \%$ of L-ADC cases (see discussion of [1]) but only in nonmucinous L-ADC. According to current guidelines, detecting an EGFR mutation should prompt administration of an EGFR tyrosine kinase inhibitor (TKI), such as gefitinib, erlotinib or afatinib, as first-line treatment [3]. Kirsten Ras (KRAS) mutations are detected in 10-30\% of L-ADC cases (see discussion of [1]). While this mutation has been shown to be primarily associated with smoking in nonmucinous L-ADC patients, it can also be found in non-smokers exhibiting mucinous L-ADC.

The IFCT-0504 trial main objective was to assess the efficacy of the paclitaxel-carboplatin doublet with that of erlotinib, when administered as first-line therapy to invasive L-ADC patients [1]. The trial successfully achieved its primary objective, with disease control rate at 16 weeks exceeding $30 \%$ in both arms. We feel that no conclusion can be drawn from overall survival data in this phase II trial, which actually used disease control rate endpoint as classically recommended for such a design. We do not find appropriate to use post hoc phase III endpoints to draw any recommendation for future trials, such as suggested in the editorial.

The IFCT-0504 trial results also revealed that mucinous L-ADCs are associated with a clearly higher differential sensitivity to chemotherapy rather than EGFR TKI when given as first-line treatment, irrespective of molecular characteristics [1]. These findings are in line with those of the IPASS (assessing gefitinib in an Asian population) [4] and TORCH (erlotinib in a Caucasian population) trials [5], both of which reported EGFR TKIs to exert deleterious effects, when administered as first-line to ADC patients without EGFR mutation. Besides harbouring KRAS mutations, mucinous L-ADCs can present other molecular abnormalities associated with resistance to EGFR TKIs, such as overexpression of insulin-like growth factor receptor 1 [6] or genetic rearrangements involving genes such as anaplastic lymphoma kinase (ALK), ROS1, or CD74-NRG1 [7, 8]. According to current guidelines, upon detecting an ALK or ROS1 rearrangement, crizotinib therapy should be proposed to the patient [3]. Considering all these issues, we do not share the proposal that a trial comparing paclitaxel-carboplatin with erlotinib in mucinous L-ADC patients be conducted. Such a trial would unjustly expose $50 \%$ of patients to TKIs, although we presently know that they might progress more quickly with this treatment than they would if given paclitaxel-carboplatin doublet [1].

Despite its methodological imperfections [2], the IFCT 0504 trial contributed several significant findings [1]. Firstly, IFCT-0504 trial was the first prospective controlled therapeutic trial worldwide to support paclitaxelcarboplatin as a treatment choice for L-ADC, a disease previously considered refractory to chemotherapy [9]. The trial also was the first to highlight the relevance of distinguishing between the nonmucinous and mucinous L-ADC subtypes for appropriate treatment selection. Lastly, the trial suggested that early assessment, i.e. as early as week 4, can allow the rapid treatment switch to avoid any deleterious effects on overall survival and that giving pemetrexed as third-line treatment may counterbalance EGFR TKI therapy failure in mucinous L-ADC patients.

Finally, the accumulated results from the IFCT trials $[1,10]$, along with our now deeper understanding of L-ADC biology, have enabled us to put forth the following: 1) it appears essential to test for oncogene addiction all invasive L-ADC cases in order to determine the best adapted personalised treatment; 2) even in the absence of any oncogene addiction, the paclitaxel-carboplatin doublet is just as efficacious, regardless of the L-ADC subtype; and 3) mucinous L-ADC cases are, owing to their biological characteristics, the form most likely resistant to EGFR TKIs. In that context, work is currently progressing within our collaborative group to design the next trial addressing therapeutic best strategy for advanced L-ADC. 
@ERSpublications

Mucinous lepidic adenocarcinoma are, owing to their biological characteristics, most likely resistant to EGFR TKIs http://ow.ly/Z3KdA

Jacques Cadranel ${ }^{1,2}$, Marie Wislez ${ }^{1,2}$, Alexandra Langlais ${ }^{2}$, Franck Morin ${ }^{2}$ and Gérard Zalcman ${ }^{2,3}$

${ }^{1}$ Chest Departement, APHP Hôpital Tenon and Pierre et Marie Curie Université Paris 6, Paris, France. ${ }^{2}$ Intergroupe Francophone de Cancérologie Thoracique (IFCT), Paris, France. ${ }^{3}$ Thoracic Oncology Dept, APHP Hôpital Bichat and Université Paris 7, Paris, France.

Correspondence: Jacques Cadranel, Service de Pneumologie Hôpital Tenon 4 rue de la Chine 75970 Paris, France.

E-mail: jacques.cadranel@tnn.aphp.fr

Received: Nov 192015 | Accepted after revision: Dec 252015

Conflict of interest: Disclosures can be found alongside the online version of this article at erj.ersjournals.com

\section{References}

1 Cadranel J, Gervais R, Merle P, et al. Erlotinib versus carboplatin and paclitaxel in advanced lepidic adenocarcinoma: IFCT-0504. Eur Respir J 2015; 46: 1440-1450.

2 Paesmans M. Should the treatment of advanced lepidic adenocarcinoma be adapted to the pathological subtype? Eur Respir J 2015; 46: 1259-1261.

3 Besse B, Adjei A, Baas P, et al. 2nd ESMO Consensus Conference on Lung Cancer: non-small-cell lung cancer first-line/second and further lines of treatment in advanced disease. Ann Oncol 2014; 25: 1475-1484.

4 Mok T, Wu YL, Thongprasert S, et al. Gefitinib or carboplatin-paclitaxel in pulmonary adenocarcinoma. $N$ Engl J Med 2009; 361: 947-957.

5 Gridelli C, Ciardiello F, Gallo C, et al. First-line erlotinib followed by second-line cisplatin-gemcitabine chemotherapy in advanced non-small-cell lung cancer: the TORCH randomized trial. J Clin Oncol 2012; 30: 3002-3011.

6 Hurbin A, Wislez M, Busser B, et al. Insulin-like growth factor-1 receptor inhibition overcomes gefitinib resistance in mucinous lung adenocarcinoma. J Pathol 2011; 225: 83-95.

7 Fernandez-Cuesta L, Plenker D, Osada H, et al. CD74-NRG1 fusions in lung adenocarcinoma. Cancer Discov 2014; 4: 415-422.

8 Nakaoku T, Tsuta K, Ichikawa $\mathrm{H}$, et al. Druggable Oncogene Fusions in Invasive Mucinous Lung Adenocarcinoma. Clin Cancer Res 2014; 20: 3087-3093.

9 Garfield DH, Cadranel JL, Wislez M, et al. The bronchioloalveolar carcinoma and peripheral adenocarcinoma spectrum of diseases. J Thorac Oncol 2006; 1: 344-359.

10 Cadranel J, Quoix E, Baudrin L, et al. IFCT-0401 Trial: a phase II study of gefitinib administered as first-line treatment in advanced adenocarcinoma with bronchioloalveolar carcinoma subtype. J Thorac Oncol 2009; 4: $1126-1135$ 